\title{
La costa occidental de la provincia de Málaga: rasgos generales de su paisaje
}

\author{
Matías F. Mérida Rodríguez, Sergio Reyes Corredera | Dpto. de Geografía, \\ Universidad de Málaga \\ URL de la contribución <www.iaph.es/revistaph/index.php/revistaph/article/view/3961>
}

\section{RESUMEN}

La costa occidental de la provincia de Málaga constituye un ámbito espacial relativamente reducido pero de un gran dinamismo. Su paisaje, articulado por dos grandes elementos, la montaña y el mar, se caracteriza por su intensa humanización, derivada en la actualidad de la actividad turística y del proceso de urbanización, pero protagonizada en décadas anteriores por la agricultura, la pesca, la minería e incluso la industria. La variedad del medio físico y las distintas modalidades de la ocupación humana han dado lugar a un paisaje de apreciable diversidad, que se traduce en la existencia de numerosos recursos paisajísticos. Al mismo tiempo, la intensidad de determinadas dinámicas territoriales ha provocado la pérdida de paisajes valiosos y hace evidente la necesidad de evitar la degradación del paisaje, uno de los principales activos de este espacio litoral.

\section{Palabras clave}

Costa del Sol | Málaga | Paisaje | Territorio | 
a senda litoral en Calahonda (Mijas) | foto Sergio Reyes, autor de todas las imágenes del artículo si no se indica lo contrario 
El litoral occidental de la provincia de Málaga conforma un ámbito comarcal relativamente pequeño pero de gran relevancia por su intenso poblamiento y por configurar un territorio de gran dinamismo socioeconómico a escala provincial y regional. Los municipios en los que se distribuye su litoral, desde Torremolinos hasta Manilva, reúnen una superficie de $658 \mathrm{~km}$, el $9 \%$ de la provincia, y concentran al $31 \%$ de la población malagueña.

Su territorio se organiza en torno a dos grandes elementos estructurantes, la montaña y el mar, que envuelven una franja litoral relativamente estrecha donde se desarrolla la actividad humana, impulsada por la benignidad climática que entre ambos proporcionan: uno, el mar, por la suavización térmica; el otro, la montaña, por la protección frente a los vientos del norte. El paisaje, históricamente y en la actualidad, viene definido por la presencia del mar y la montaña. El carácter agrario tradicional se sustentaba en estas particularidades climáticas, de igual forma que su actual personalidad residencial y turística. La disposición paralela de la costa y la montaña convirtió a esta comarca en territorio de tránsito, con ejes de comunicaciones muy importantes, tanto en el modelo territorial histórico como en el actual, ya que supone la conexión entre ámbitos tan relevantes como la capital malagueña y el campo de Gibraltar. Como efecto contrario, las conexiones con el interior son más complicadas, sobre todo con Ronda y, en menor medida, con la comarca del Guadalhorce, a través de los intrincados terrenos que llevan a los puertos de Ojén y Los Pescadores (Mijas). Esta condición de territorio

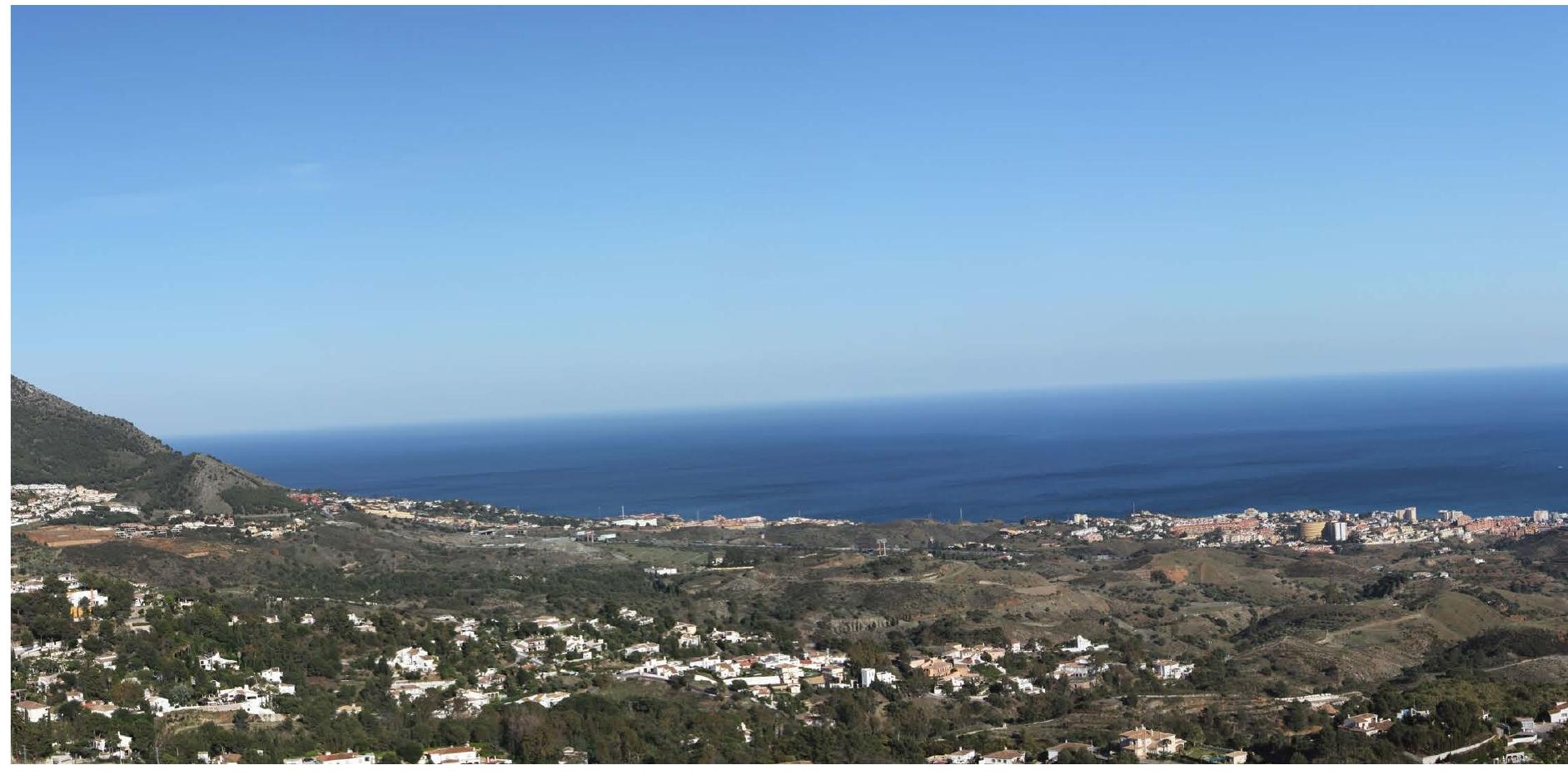


ral de las cordilleras béticas y sus estribaciones, y se dispone a lo largo de toda la costa, generando una estructura de tres niveles: los macizos principales (sierras de Mijas, Alpujata, Blanca, Bermeja, Crestellina), un escalón más bajo ocupado por sus estribaciones, y finalmente una estrecha franja litoral. Únicamente en la parte central se distancian las principales elevaciones algo más de la línea de costa, generando un espacio amplio de colinas y valles, el campo de Mijas. En la parte más occidental, el abrigo montañoso disminuye notablemente, siendo la conexión con el interior más suave a través de un paisaje de colinas. En general, las cumbres más destacadas de la alineación principal no son excesivamente elevadas, entre 1.000 y 1.500 metros en líneas generales, pero su cercanía al mar (entre 5 y 10 kilómetros en muchos casos) genera considerables desniveles y aumenta la percepción de su altura.

Hay una clara diferenciación de roquedo entre los macizos montañosos, alternándose los materiales calcáreos (sierras de Mijas, Blanca, Crestellina, Utrera) con los ultrabásicos (peridotitas), que aparecen en la sierra de Alpujata y sobre todo en Sierra Bermeja y sus prolongaciones. Esta diferencia se aprecia claramente en el paisaje: las sierras calcáreas poseen una tonalidades claras mientras que en las peridotitas predominan los colores rojizos; de ahí la toponimia: Sierra Blanca de Mijas, Sierra Blanca de Marbella, Sierra Bermeja, Sierra Parda de Ojén. Los piedemontes suelen ser pizarrosos, excepto en la parte más oriental (Torremolinos), donde lo conforma el propio glacis calcáreo de la sierra de Mijas. En ocasiones, estos piedemontes contactan directamente con el mar, formando fragmentos de costas acantiladas; no obstante, la mayor parte del litoral está compuesto de playas arenosas, interrumpidas por los puertos pesqueros y deportivos que lo jalonan. En las zonas más próximas a la costa se han depositado sedimentos postorogénicos, tanto marinos (Manilva, entorno de Fuengirola) como aluviales. Estos sedimentos tienen una gran trascendencia paisajística, ya que han dado lugar a los mejores suelos agrícolas del espacio litoral.

El clima constituye un factor de clara repercusión paisajística. La benignidad climática favorece el desarrollo turístico y residencial y el desarrollo de cultivos como la vid, los frutales subtropicales o, antiguamente, la caña de azúcar. Debido a la influencia marina, la comarca registra temperaturas suaves en el contexto mediterráneo, tanto en verano como, especialmente, en invierno. Las precipitaciones son, en general, medias y altas, creciendo de este a oeste: alrededor de $500 \mathrm{~mm}$ anuales en Torremolinos, más de 800 en Estepona y Casares. Esta humedad explica en parte la abundante vegetación natural existente en la parte occidental: coníferas en las sierras peridotíticas y alcornoques en el piedemonte. No obstante, la climatología no explica totalmente la menor cobertura vegetal de otras zonas montañosas litorales, deforestadas en el siglo XIX por las talas para la industria, los usos tradicionales (carboneo, roturaciones) y más recientemente por los incen- 

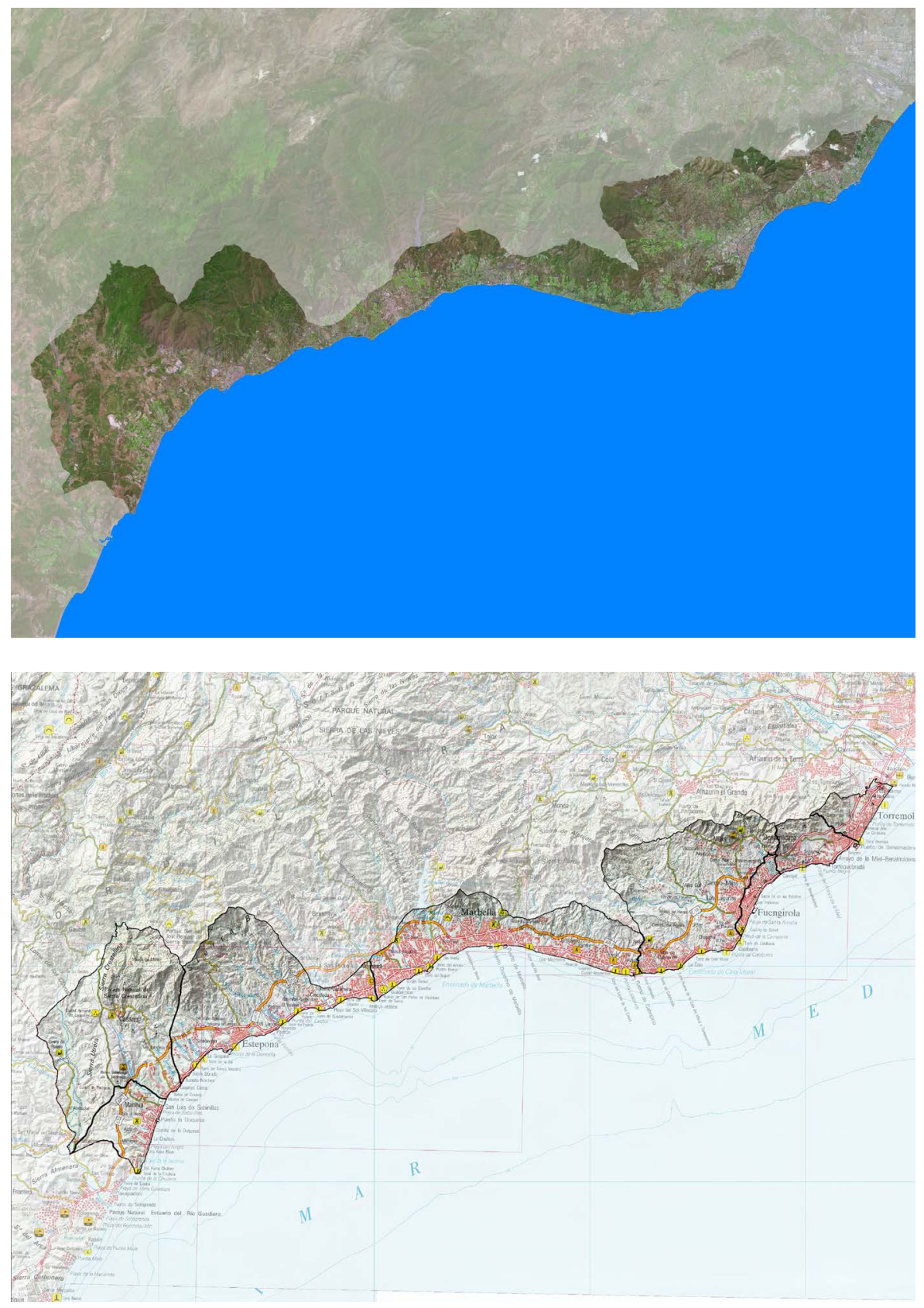

Ortofotografía del ámbito de estudio | elaboración propia a partir de IGN. Plan de Ortofotografía Aérea

Ámbito de estudio | elaboración propia a partir de IGN. Plan de Ortofotografía Aérea

dios forestales. Además, el roquedo calcáreo condiciona el desarrollo o la regeneración de formaciones densas, lo que explica las repoblaciones forestales efectuadas, siendo pioneras las efectuadas en las primeras décadas del siglo XX en la sierra de Mijas. Las repoblaciones son responsables también de una de las imágenes más emblemáticas del litoral: los pinares entre Marbella y Calahonda, plantados durante el siglo XX para impedir el avance 
de las formaciones dunares y que prácticamente han sustituido a los alcornocales originales.

Los ríos aparecen también como ejes estructurantes del territorio. En su parte occidental, la red hidrográfica la conforman ríos perpendiculares a la línea de costa, cortos, próximos entre sí, y con un caudal anual apreciable, procedente de las altas precipitaciones de las sierras cercanas. Sobre uno de ellos, el río Verde, se sitúa el homónimo embalse, el único de la comarca. El régimen de estos ríos, no obstante, está marcado por la típica irregularidad mediterránea. Sus abundantes aportes de sedimentos han contribuido al desarrollo de la llanura litoral, especialmente en la zona de San Pedro de Alcántara, donde confluyen las desembocaduras de los ríos Guadaiza y Guadalmina. Más al este, en la parte central de la comarca, se sitúa el río Ojén-Fuengirola, el colector más destacado y el que posee la cuenca hidrográfica más extensa; en cambio, por la parte más oriental, en Benalmádena y Torremolinos, la cercanía de las montañas da lugar sólo a la formación de pequeñas torrenteras encajadas entre las colinas y rampas que conforman el piedemonte serrano.

La trascendencia paisajística del agua no se limita a las aguas superficiales. Las aguas subterráneas poseen una gran relevancia en la formación del paisaje. La existencia de grandes sierras calcáreas, muy permeables, ha dado lugar a la formación de importantes acuíferos y al asentamiento de núcleos en torno a sus manantiales. Torremolinos, Benalmádena y Mijas, entre otros, deben a esta disponibilidad hídrica su emplazamiento, íntimamente asociado también a la presencia de rocas generadas por la precipitación del carbonato cálcico, los travertinos.

Estas formaciones dan lugar a resaltes sobre el terreno que, además de dar lugar a la formación de estos núcleos, están dotados habitualmente de importantes valores simbólicos y religiosos. Por último, las aguas subterráneas se utilizaban también como fuente de energía en los molinos que

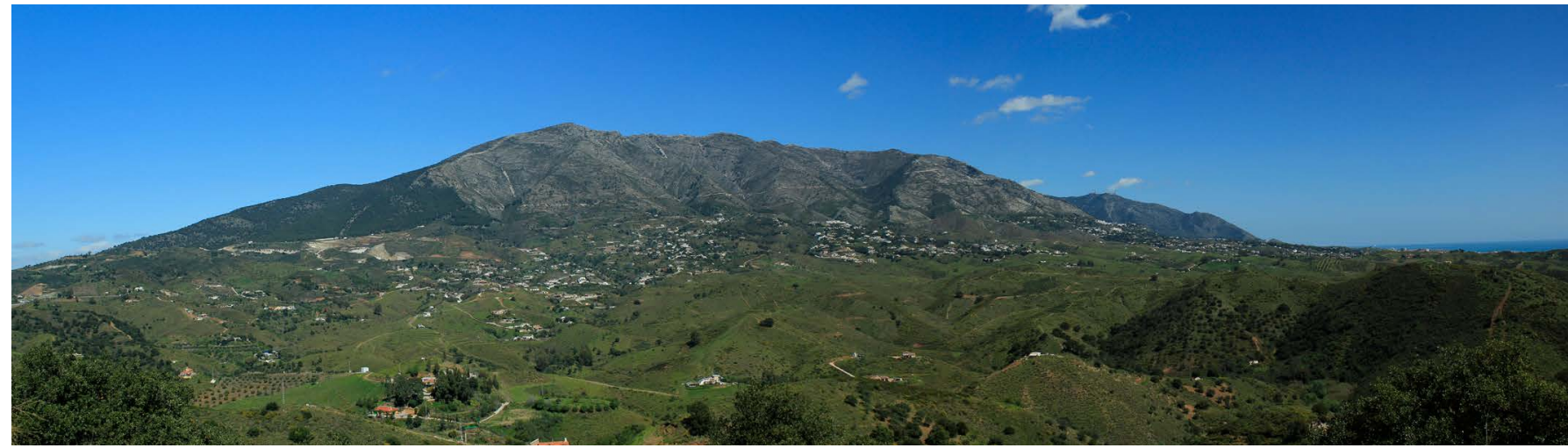


las aprovechaban para moler el cereal, por ejemplo en Torremolinos o en Casares.

Sobre esta base física, las características de su paisaje se derivan también de la construcción histórica del territorio, especialmente intensa durante la segunda mitad del siglo XX. Hasta esa época de cambio, el modelo territorial tradicional estaba basado en el sector primario, tanto agrario como pesquero. En algunos casos, dualmente, como en Torremolinos, que contaba con su núcleo tradicional, sobre el acantilado, y su apéndice pesquero sobre la propia línea de costa, el barrio de la Carihuela, o como en su momento Mijas y Fuengirola. En general, el espacio agrario se vinculaba a la llanura litoral, a las colinas de sedimentación marina (Manilva, por ejemplo) y a las montañas medias pizarrosas. Entre los cultivos más extendidos se encontraba el cereal, la vid (hasta la crisis de la filoxera), los frutales (de secano en los piedemontes y de regadío en las llanuras) y los cultivos de huerta de la zona litoral, junto al ya desaparecido cultivo de la caña de azúcar. Como singularidad habría que destacar el caso de la colonia de San Pedro de Alcántara, fundada a mediados del siglo XIX y concebida como una gran y moderna explotación agrícola de regadío. Junto al sector primario, los recursos mineros de la montaña (explotados desde antiguo) dieron lugar durante el siglo XIX a un cierto desarrollo industrial en torno a Marbella, tanto de tipo siderúrgico (basado en la explotación de las minas de hierro de Ojen y Marbella) como agroalimentario (explotación industrial de la caña de azúcar), quedando de esta temprana industrialización diversos vestigios patrimoniales.

La segunda mitad del siglo XX está dominada por el desarrollo del turismo y la consiguiente expansión de los espacios turísticos y de los núcleos de población, así como por la reducción y en algunos casos especialización del espacio agrícola. Aunque el origen y primer desarrollo del turismo desde finales de los años 50 se relacionó con pioneros establecimientos hoteleros de calidad (Castillo Santa Clara o Pez Espada en Torremolinos, Marbella Club en Marbella), en las siguientes décadas los espacios turísticos

Vista del litoral. Término municipal de Benalmádena

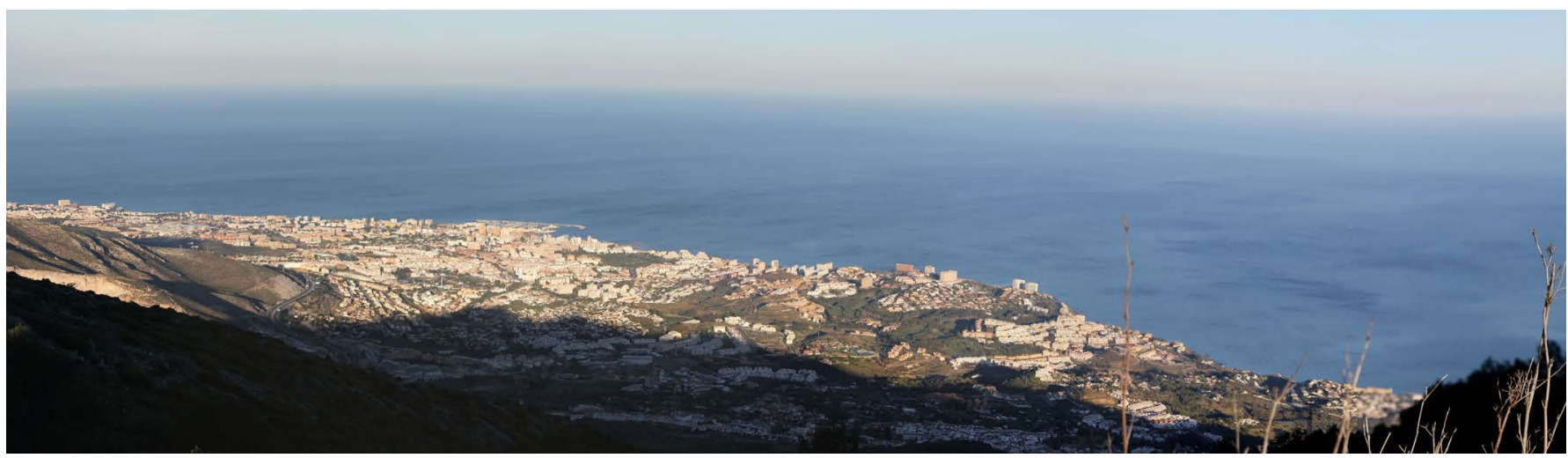



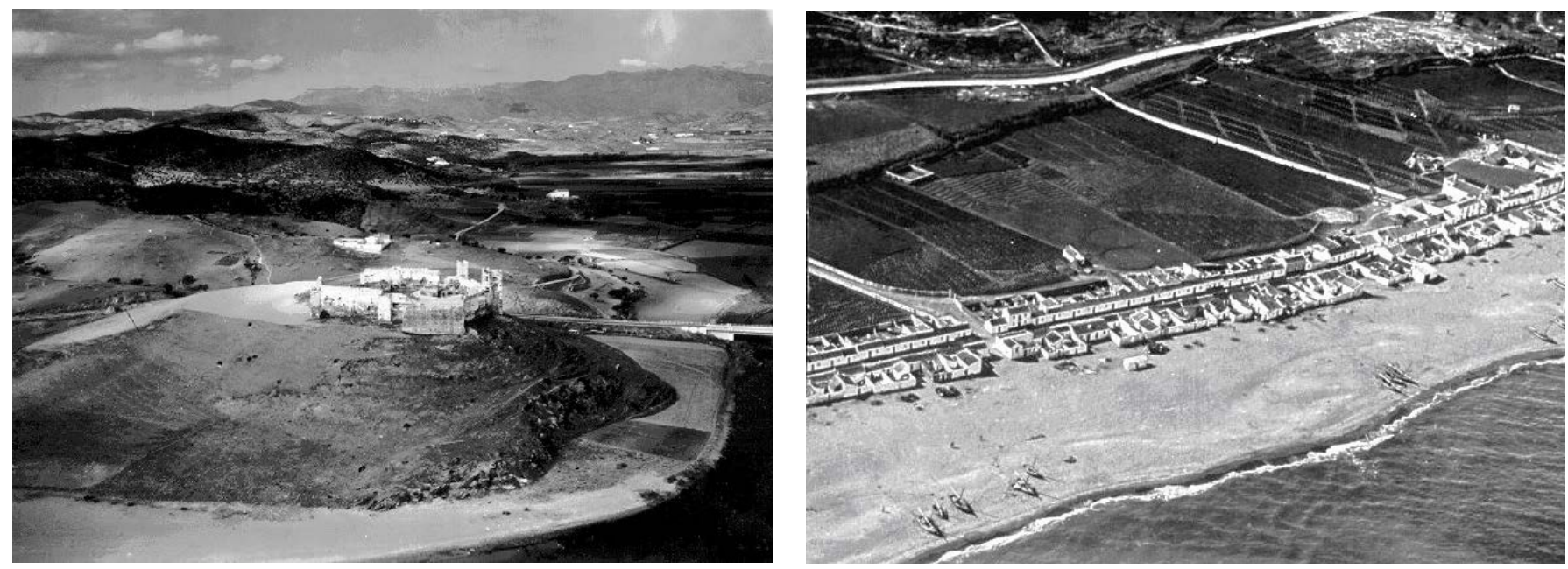

Vista del castillo de Sohail (Fuengirola) hacia 1950 foto Archivo Temboury

Imagen de La Carihuela (Torrremolinos) hacia 1950 Memories of Torremolinos se extendieron por el conjunto del litoral de una forma masiva, en muchas ocasiones poco respetuosa con el paisaje. A veces, en los propios núcleos (Fuengirola), en otras ocasiones mediante el desarrollo de apéndices turísticos, como Benalmádena Costa, y sobre todo a través de urbanizaciones, tanto en la zona litoral como, en un segundo momento, en áreas algo más interiores pero con mayor calidad ambiental. Estas urbanizaciones están compuestas mayoritariamente de chalés de tipologías unifamiliares, de estilos que incorporan elementos vernáculos (color blanco en los paramentos, teja árabe) y con piscina. En numerosas ocasiones se emplazan junto a campos de golf, que se han terminado erigiendo como un destacado componente del paisaje turístico costasoleño.

Al mismo tiempo, aupados por este desarrollo turístico, los núcleos tradicionales experimentaron un gran desarrollo por la llegada de trabajadores relacionados con la actividad constructiva y turística, tanto en las cabeceras municipales como en asentamientos como San Pedro de Alcántara, en Marbella, Arroyo de la Miel (Benalmádena), las Lagunas (Mijas) o Sabinillas (Manilva). Más recientemente, el proceso de metropolización de la aglomeración urbana malagueña ha dado lugar a un importante crecimiento de los municipios más orientales, como Torremolinos o Benalmádena. Como resultado, el espacio construido ha crecido enormemente en toda la comarca, hasta alcanzar el $26 \%$ de la superficie de los términos municipales litorales, cuando en 1956 apenas suponía el 1\%. Por el contrario, los terrenos agrícolas han disminuido drásticamente: de ocupar el $30 \%$ de la superficie en 1956 ha pasado a representar apenas el 10\% en la actualidad. Exceptuando el caso de Manilva, en el que el viñedo se ha mantenido como principal uso del suelo, el espacio agrario ha quedado reducido a las franjas periurbanas de Estepona y Mijas, vinculado a cultivos más productivos, como los cítricos de Estepona y Casares (estos últimos en el más interior valle del Genal) y 


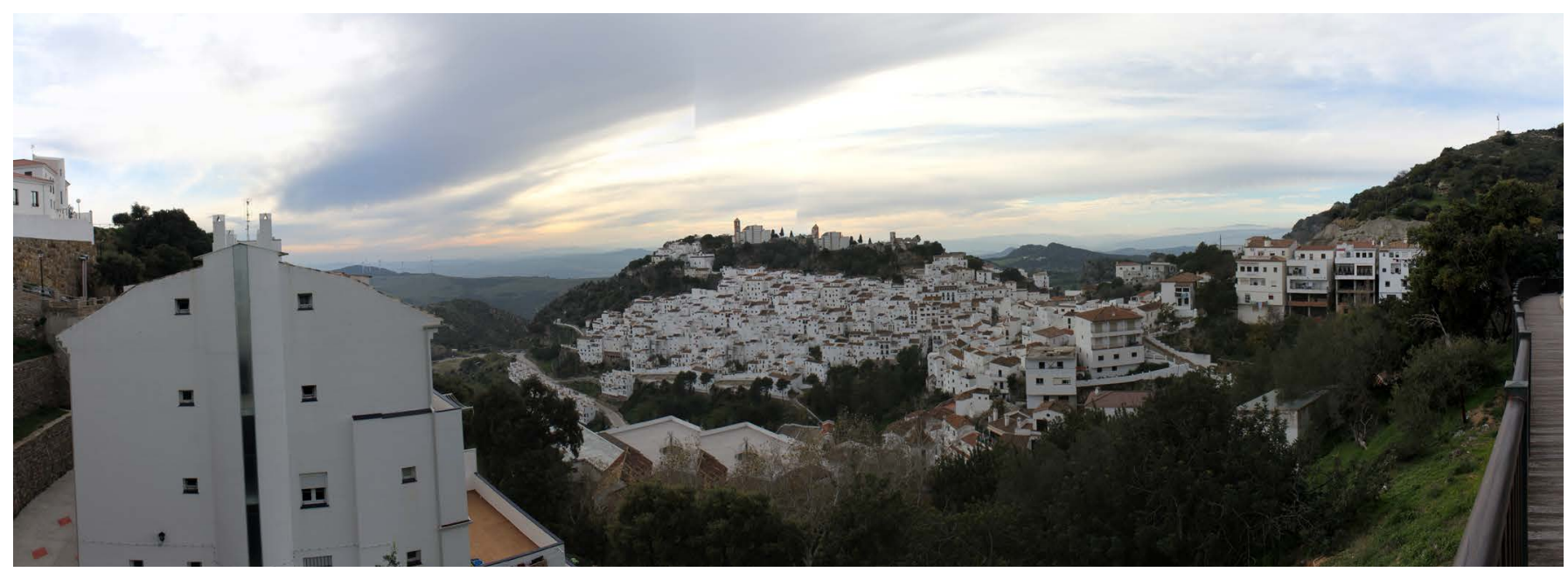

Vista del núcleo de Casares

los frutales subtropicales (Mijas), mientras que las tierras más marginales siguen estando ocupadas por cultivos de secano como el almendro o el olivar. El espacio industrial, antaño una actividad importante, posee hoy una importancia muy reducida.

Los recursos paisajísticos de la comarca responden, por un lado, a componentes del medio natural y, por otro, a elementos del patrimonio cultural. Entre los primeros, sobresalen las principales elevaciones del relieve, verdaderos dominadores del paisaje de la comarca. Cumbres como los Reales, en Sierra Bermeja, La Concha, en Sierra Blanca de Marbella, o los picos de Mijas, Cerro del Moro o El Calamorro, en la Sierra de Mijas, constituyen puntos de referencia visual y simbólica de primer orden. Estas alineaciones montañosas albergan espacios naturales de gran calidad paisajística, como el pinsapar de Los Reales, los pinares de las sierras de Marbella y Mijas, el alcornocal de Casares o el paisaje kárstico de la sierra de la Utrera. Parte de estos espacios naturales, tanto montañosos como fluviales, gozan de protección ambiental, bien como parajes naturales en la Red de Espacios Naturales Protegidos de Andalucía (Sierra Crestellina, Los Reales de Sierra Bermeja), bien como Zonas de Especial Conservación de la red Natura 2000, o bien, bajo diversas figuras, en el PEPMF de la provincia de Málaga. Algunos terrenos serranos (Sierra Real, Sierra de Ojén) forman parte de la Reserva de la Biosfera de la Sierra de las Nieves, aunque no de su cercano parque natural, para el que existe una propuesta de declaración de Parque Nacional, al igual que, desde otras instancias, para Sierra Bermeja.

En el litoral, además de las desembocaduras de los ríos, perviven vestigios de formaciones naturales, como las dunas de Cabopino (Marbella), esquilmadas en el siglo pasado como material para la construcción y hoy protegidas como monumento natural. 
Numerosos componentes del patrimonio cultural histórico aúnan a su valor intrínseco una potente dimensión paisajística, que los hace ser percibidos como hitos en el paisaje. Algunos, como el castillo de Fuengirola, por su singularidad y por su emplazamiento en un promontorio aislado junto al litoral. Otros, como la veintena de torres vigías que jalonan el litoral, por su estructura en red, distribuida de modo prácticamente regular por toda la costa. Aunque hay algunas de origen nazarí, la mayoría fueron construidas a lo largo de la edad moderna como elementos de vigilancia del litoral, y prácticamente todas están declaradas como BIC. Asociadas al espacio costero también se sitúan las fortalezas litorales, como el castillo de Sabinillas (Manilva), el de San Luis (Estepona) o la batería de La Cala de Mijas. Aunque mucho menos numerosos, una función paisajística parecida a la de las torres vigía juegan los faros, algunos de ellos de carácter ya histórico, como los de Calaburras (Mijas) o Punta Doncella (Fuengirola), o el más reciente de Marbella. Entre ellos, es el de Calaburras el que ejerce una función referencial más potente, al situarse en un entorno menos urbanizado.

El patrimonio industrial recoge testimonios igualmente interesantes y con una clara dimensión paisajística, como el ingenio de San Pedro de Alcántara, los trapiches del Prado (Marbella) o de Guadaiza, en San Pedro de Alcántara y los restos de la ferrería de la Concepción, en Marbella. Más reciente es el cargadero de mineral de hierro existente en la costa de Marbella, denominado El Cable, cuyos restos son visibles en el mar.

Por su parte, los núcleos de población con características históricas constituyen recursos paisajísticos igualmente destacados, y poseen una innegable dimensión económica que emana, precisamente, de su calidad paisajística, como ocurre en los casos de los núcleos o centros históricos de Casares, Estepona, Marbella, Mijas o Benalmádena. Tanto el núcleo de Casares (1978) como el de Mijas (1969) están declarados como BIC, en la categoría de conjunto histórico. Tomando como muestra la declaración de Mijas, en su justificación se incluye tanto el tipismo de las casas y calles como su emplazamiento en un entorno montañoso y boscoso, con la consiguiente calidad de sus panorámicas.

Las construcciones históricas más prominentes, como los castillos (Sohail, en Fuengirola, Marbella, Estepona, Casares), poseen también una destacada vertiente paisajística y un alto valor como componente de identidad para sus poblaciones. Por su parte, ciertas edificaciones y paisajes surgidos de la actividad turística se van incorporando progresivamente al patrimonio paisajístico y algunas de ellas gozan de protección arquitectónica como destacados exponentes de la arquitectura contemporánea. Algunos ejemplos son la Ciudad Tiempo Libre, el hotel Don Carlos o la urbanización Los Monteros, todos ellos en Marbella, o el Colegio de Huérfanos Ferroviarios (declarado BIC) y el Hotel Pez Espada, ambos en Torremolinos. 

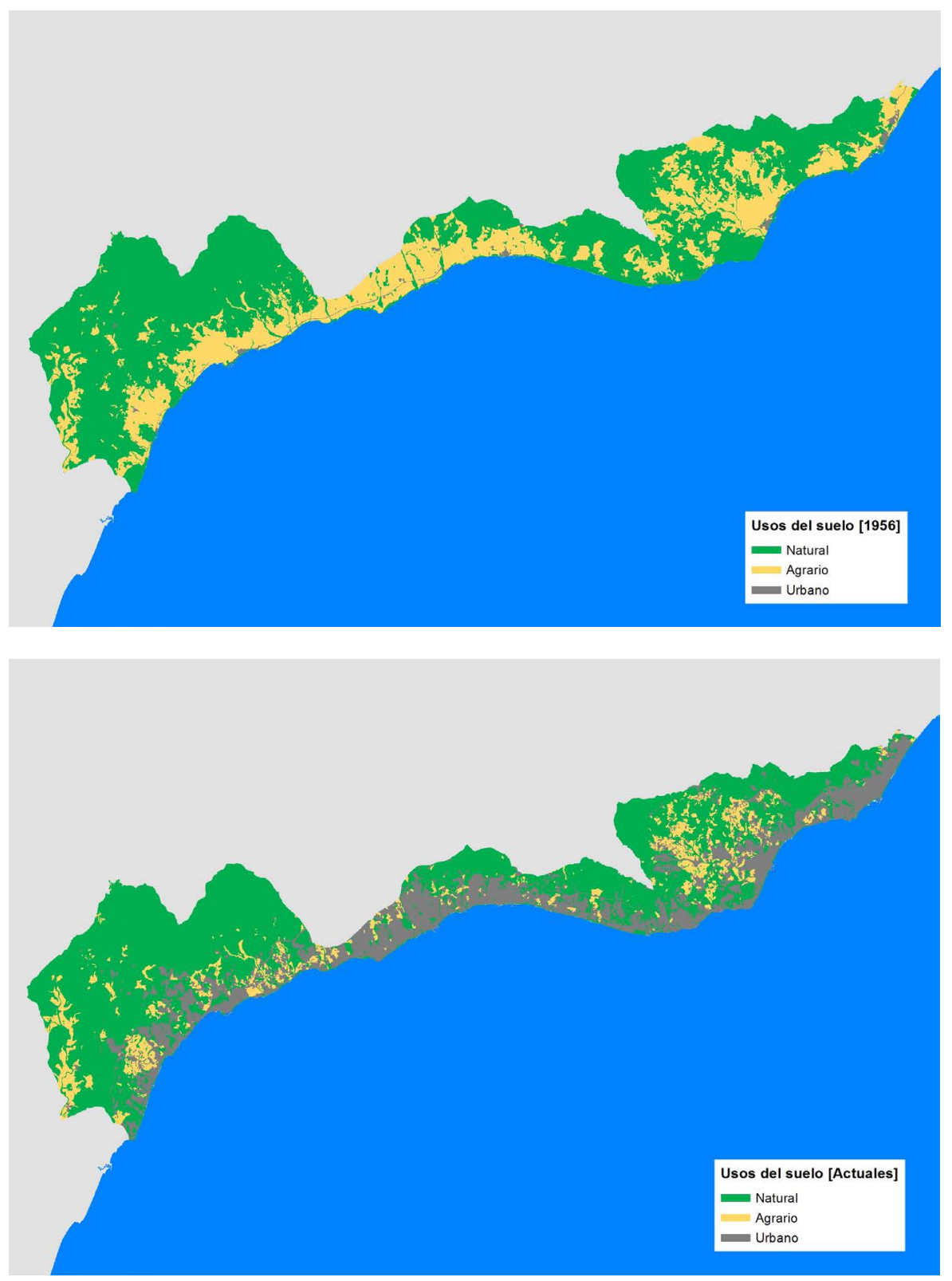

Grandes usos del suelo en 1956 | mapa elaboración propia

Grandes usos del suelo en 2007 | mapa elaboración propia

Además de los recursos, es necesario resaltar la destrucción de paisajes que determinados procesos, básicamente el desarrollo turístico, han provocado en un territorio que, de haber experimentado un modelo de desarrollo más sostenido, sin duda hubiera dado lugar a la creación de espacios de gran calidad paisajística y turística, como afortunadamente todavía ocurre en determinadas zonas de la costa de Marbella. Sin embargo, la costa del sol occidental está lejos de ser un espacio turístico terminado, sino que, al contrario, se trata de un territorio con un intenso dinamismo, por lo que 
determinadas dinámicas siguen amenazando con alterar su paisaje, como la penetración de la urbanización en zonas interiores y de montaña, la alteración de perspectivas valiosas por la construcción intensiva, la degradación de los espacios periurbanos por procesos de urbanización difusa, las cicatrices producidas en las montañas por la actividad extractiva (hoy en desuso, excepto en Casares), los impactos de la construcción de grandes infraestructuras viarias, etc. El dinamismo económico ni puede ni debe pararse, pero es necesaria la introducción de criterios paisajísticos en el diseño de nuevas actividades, así como la recuperación paisajística de espacios degradados. Todo ello no desde una perspectiva únicamente de protección (y concienciación) del patrimonio paisajístico, de por sí importante, sino también para evitar la degradación de un recurso turístico de primer orden en un territorio vinculado tan estrechamente al turismo. 


\section{BIBLIOGRAFÍA}

- ARENAS GómeZ, A. et ál. (1998) Historia de la Costa del Sol. Málaga: Diario Sur, 1998

- DURÁN VALSERO, J. J. (coord.) (2007) Atlas hidrogeológico de la provincia de Málaga. Málaga: IGMEDiputación provincial de Málaga, 2007

- ESCORZA DOBLAS, F. (2001) El turismo del golf en la Costa del Sol. Análisis geográfico. Málaga: Diputación de Málaga, 2001

- GALACHO JIMÉNEZ, F. B. (1996) Urbanismo y turismo en la Costa del Sol. Málaga: Universidad de Málaga, 1996

- GALACHO JIMÉNEZ, F. B.; LUQUE GIL, A. M. (2000) La dinámica del paisaje de la Costa del Sol desde la aparición del turismo. Baetica, (20), 2000, pp.25-5

- GARCía MANRIQUE, E. (1984) La Costa occidental malagueña. En VV. AA. Málaga, tomo 1. Granada: Editorial Anel, 1984, pp. 229-260

- GOMEZ MORENO, M. L. (1989) La montaña malagueña: estudio ambiental y evolución de su paisaje. Málaga: Diputación provincial de Málaga, 1989

- GómEZ ZOTANO, J. (2006) Naturaleza y paisaje en la Costa del Sol Occidental. Málaga: Diputación de Málaga, 2006

- López aragón, N.; SÁNCHez PACHeCHO, A. (dir.) (2010) Guía turística cultural de la Mancomunidad de municipios de la Costa del Sol. Málaga: Mancomunidad de Municipios de la Costa del Sol Occidental, 2010

- MORALES FOLGUERA, J. M. (1982) La Arquitectura del Ocio en la Costa del Sol. Málaga: Universidad de Málaga, 1982

- NAVARRO JURADO, E. (2003) ¿Puede seguir creciendo al Costa del Sol? Indicadores de saturación de un destino turístico. Málaga: Diputación de Málaga, 2003

- OLANO, A. D. (1974) Guía secreta de la Costa del Sol. Madrid: Al-Borak, 1974

- PÉREZ DE LA FUENTE, I. (1998) El turismo en la costa del sol y la producción del espacio del placer. Málaga: Colegio de Arquitectos de Málaga, Ayuntamiento de Málaga, 1998

- ZoIDO NARANJO, F.; RODRÍGUEZ RODRÍGUEZ, J. (2015) (dir.) Catálogo de Paisajes de la provincia de Málaga (Archivo digital). Sevilla: Centro de Estudios Paisaje y Territorio, Consejería de Medio Ambiente y Ordenación del Territorio, 2015 